\title{
Retropharyngeal fibrolipom in adults: a case report
}

\begin{abstract}
Fibrolipomas have been defined as a subtype of lipomas that are benign soft tissue tumors according to the WHO classification. Fibrolipomas have been described in the esophagus, pharynx, colon, trachea and larynx. They may be seen in the oral cavity and in the maxillofacial area. Tumors of the retropharyngeal region are extremely rare. Our case is the $3^{\text {rd }}$ retropharyngeal fibrolipomas in the literature.
\end{abstract}

Volume 8 Issue 8 - 2017

\author{
Sanem Oksan Erkan,' Zeynel Abidin Erkan,' \\ Birg I Tuhanio lu,' Zekiye G ney' \\ 'Department of Otorhinolaryngology and Head Neck Surgery, \\ Adana Numune Training and Research Hospital, Turkey \\ ${ }^{2}$ Department of Otorhinolaryngology and Head Neck Surgery, \\ Cukurova State Hospital,Turkey
}

\begin{abstract}
Correspondence: Sanem Oksan Erkan, Department of Otorhinolaryngology and Head Neck Surgery, Adana Numune Training and Research Hospital, Saricam Mah., Saksi Cicegi Cd., 01260 Yüreğir/Adana, Turkey, Emailsanemyilmaz67@yahoo.com
\end{abstract}

Received: September 27, 2017 | Published: December 29,

2017

\section{Introduction}

Fibrolipomas have been defined as a subtype of lipomas that are benign soft tissue tumors according to the WHO classification. ${ }^{1}$ They differ from classic lipomas with being connective tissue bands involved among the mature adipose tissues. ${ }^{2}$ Fibrolipomas have been described in the esophagus, pharynx, colon, trachea and larynx.., ${ }^{3,4}$ Rarely may they be seen in the oral cavity and in the maxillofacial area. In the oral cavity, fibrolipomas are most commonly found in the buccal region followed by tongue, lower lip and the parotid region; respectively. ${ }^{5,6}$ Retropharyngeal space is an area extending from the skull base to the mediastinum, located between the middle and deep layers of the cervical fascia. It contains a small amount of fatty tissue and chains of lymph nodes especially at the suprahyoid level. ${ }^{7}$ Lymph nodes and lymphatic channels are the main components of this space. ${ }^{8,9}$ Tumors of the retropharyngeal region are extremely rare. The most commonly seen mass is in a form of inflammatory or tumorous lymph node enlargement. ${ }^{7}$. Reported cases of lipomas in this region are less than 40 in the literature. ${ }^{10}$ Whereas retropharyngeal fibrolipoma was reported by Huang in a 17 -year-old male patient in 2008 and by Ganakalyane.

\section{Case report}

A 37-year-old female patient presented to our clinic with the complaints of severe respiratory distress and malnutrition. Her complaints were existed since more than five years. The patient had no pain complaint. Medical history of the patient revealed diabetes and epilepsy for which she was regularly using antiepileptics and oral antidiabetics. Laboratory outcome was normal except glucose. At her physical examination palatal movements and the tonsils were normal, we found submucosal swelling beginning from the posterior wall of the nasopharynx, extending toward the inferior direction. In laryngoscopy, epiglottis and vallecula was seen, but the other endolaryngeal formations could not be seen. There was a $6 \times 4 \mathrm{~cm}$ soft, painless mass at the right side of the neck. In CT, a giant mass of fat density was monitored in the prevertebral space, beginning from the nasopharyngeal region, extending markedly toward both laterals, advancing from the anterior of the SCM (sternocleidomastiod), filling the carotid spaces and extending to inferior of the thyroid lobe and the thoracic inlet in the right. No pathologic lymphadenopathy was monitored. Trachea was deviated to the left.After receiving consent from the patient; operation was scheduled for the mass which was found to not invade surrounding muscular structures, with the presumed diagnosis of lipoma. Because the patient had severe respiratory distress and intubation might be challenging, tracheotomy was opened under local anesthesia. The operation was continued under general anesthesia administered from the tracheotomy. Davis-Boyle mouth gag was inserted and the mass was observed in the oropharynx. Longitudinal mucosal incision was intraorally made over the mass in the posterior pharyngeal wall. Mucosal flaps were removed at both sides. Since lipoma was unencapsulated and very large, it could not be excised in a single piece. Excision was carried out in the area with surgical sight provided. The incision was sutured following hemostasis. The operation was completed without complication. The specimen was sent to pathology. A nasogastric tube was inserted in the patient during surgery. The patient who received postoperative clinical follow-up was fed with nasogastric tube for 14 days which was then removed. Care of tracheotomy was made. Tracheotomy was closed in the patient whom respiratory distress was resolved at the $15^{\text {th }}$ day. Postoperative pathology was reported as fibrolipoma. No grow was observed on CT ordered at the $3^{\text {rd }}$ month. The patient is currently in her postoperative $1^{\text {st }}$ year and has no any recurrence (Figures $4 \& 5$ ).

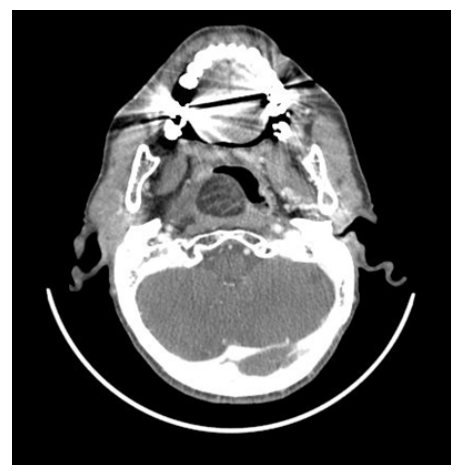

Figure I 


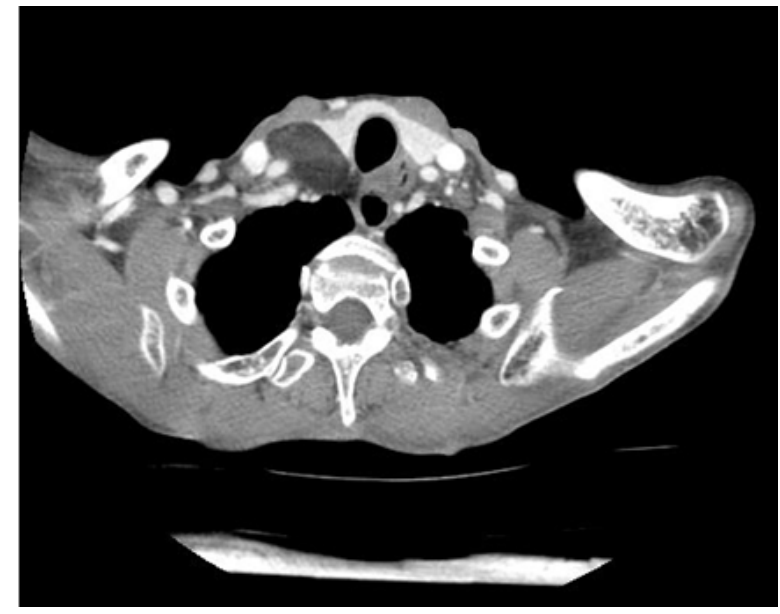

Figure 2

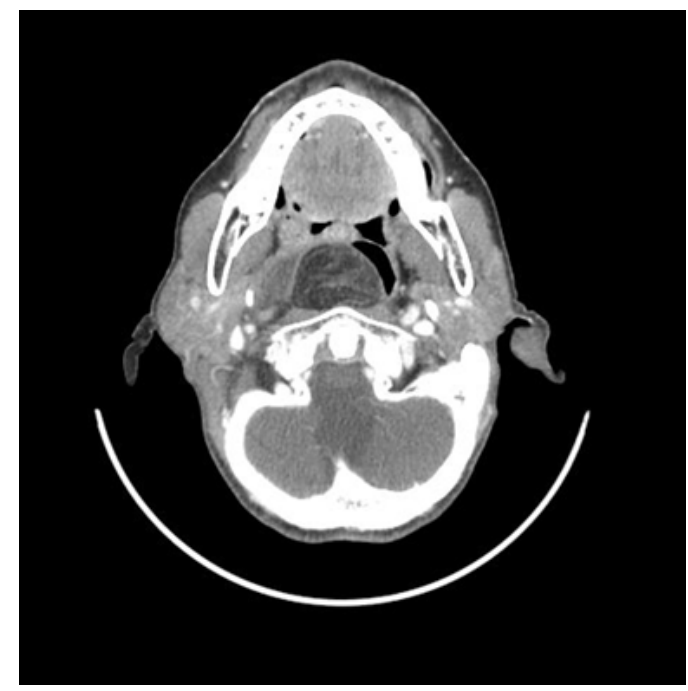

Figure 3

Figure I-3 Axial ct scan showing fat density mass in retropharyngeal space.

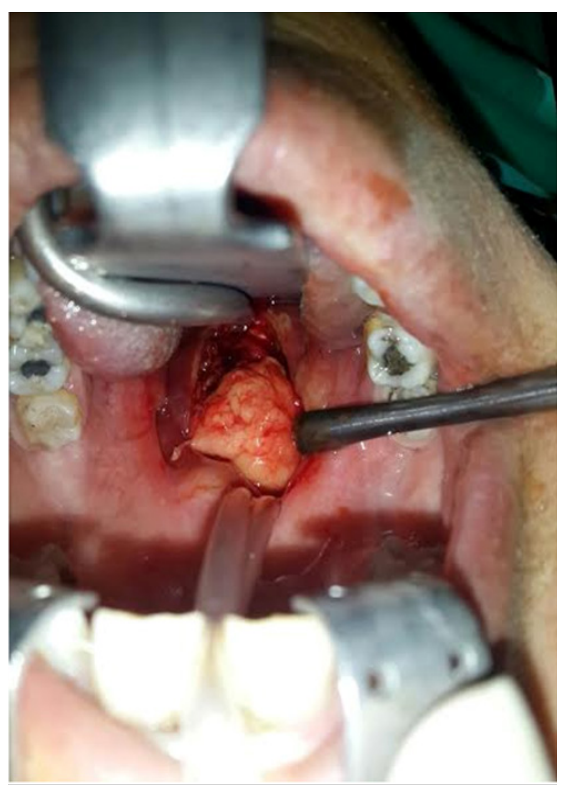

Figure 4 Intra operative lipom excision.

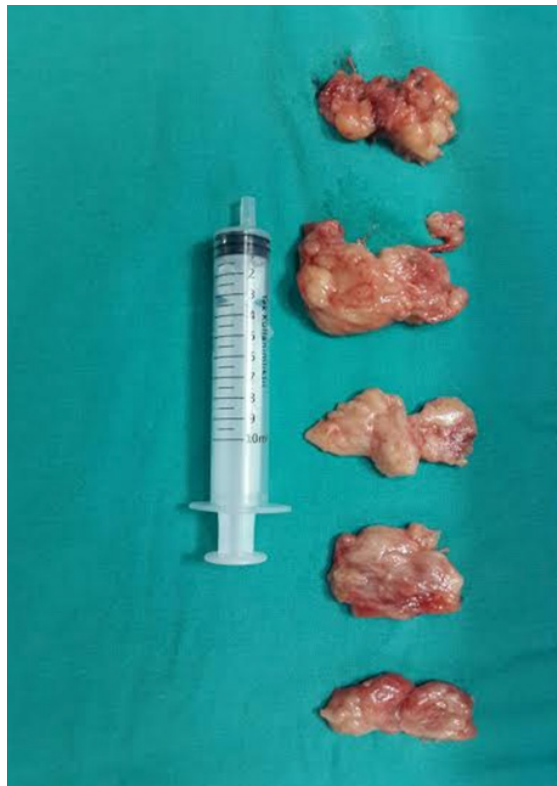

Figure 5 Photograph of excised specimen.

\section{Discussion}

Lipomas are the most common slow-growing benign soft tissue mesenchymal tumors arising from the lipocytes. Lipomas in the head-neck region are most frequently seen in the posterior of the cervical triangle. ${ }^{13}$. Oral cavity involvement is rare in lipomas (1$4 \%){ }^{5}$. In the oral cavity the most involved regions include buccal mucosa, tongue, palate, floor of mouth and vestibule. ${ }^{14}$. Whereas, retropharynx is still recognized as a rarely involved region with often infrahyoid part of this region being involved. Lipomas are most frequently observed at the $6^{\text {th }}$ decades with no gender difference. ${ }^{15}$. Lipomas have been classified as simple lipoma, fibrolipoma, spindle cell lipoma, intramuscular lipoma or infiltrating lipoma, salivary gland lipoma and myxoid lipoma. ${ }^{16}$. According to a study, $27 \%$ of lipomas found in the oral cavity have been reported as fibrolipomas. ${ }^{6}$ Retropharyngeal space is an area bounded by the buccopharyngeal fascia anteriorly and the alar fascia posteriorly which cause infections and malignant spread because its fatty tissue and lymphatic tissue content. These tumors show no symptom since they grow slowly due to the expanding feature of the retropharyngeal space. The most common symptoms are OSAS, wheezy breathing, snoring, dyspnea and dysphagia. ${ }^{17}$ These tumors often remain asymptomatic until reaching to a critical size which may create mass impact on the surrounding structures. Therefore, the diagnosis usually delays until the mass reaches to a size which may lead to dysphagia or airway obstruction. ${ }^{10}$ In our case, despite her complaints had lasted for more than five years, the patient delayed his presentation since she had felt no pain and tracheotomy was opened local because of the challenging intubation. A total of 14 retropharyngeal lipoma cases have been published within the last 14years (2000-2013).Simple lipoma is the most commonly seen subtype in the retropharyngeal space. Ganakalyan et al. ${ }^{12}$ published retropharyngeal fibrolipoma in a 2-year-old male pediatric patient and Huang et al. ${ }^{11}$ published a 17 year old boy.Our case is the first retropharyngeal fibrolipoma seen in middle age, but the third retropharyngeal fibrolipoma in the literature. Radiology is pathognomonic. On CT, it is observed as nonenhancing, smooth contoured and mostly homogeneous areas. Sometimes thin septa may be found in the internal structure. ${ }^{18}$ On 
MRI, it seems as a mass of high signal intensity in the both suppressed sequences on the fat suppressed images. ${ }^{19}$ Differential diagnosis includes well-differentiated liposarcoma. Cytological examination is not meaningful since it is similar in both conditions. Although the definitive diagnosis is established after biopsy, most authors believe that these two conditions can be radiologically distinguished. The main point is septa. Whereas septa are thin and smooth in lipoma, well-differentiated liposarcoma has thick and nodular septa. ${ }^{20}$ The giant mass in our case was compatible with lipoma.

Classical treatment of large and deep-localized symptomatic lipomas is wide surgical excision involving the capsule and partly surrounding tissue. Reoperation, consent of tracheotomy should be received for the difficulty of intubation. We also first opened local tracheotomy after receiving consent from our patient. Retropharyngeal lipoma surgery can be transcervical, submaxillary, transmandibular, transparotid, transoral or infratemporal. However, excision of retropharyngeal lesions is very difficult. Because the mass in our case was unencapsulated and extending up to the thoracic inlet, it was excised in 4 separated pieces with the maximum piece being $4 \times 2 \times 3 \mathrm{~cm}$ in size. Lee et al. ${ }^{21}$ have removed an encapsulated lipoma in a single piece. ${ }^{21}$ Namyslowski et al. ${ }^{17}$ excised the mass transcervically in a 40 -year-old male patient. ${ }^{17}$ Since our patient rejected interference with the other ways, we did not consider a more invasive intervention. There are two cases in the literature that were not operated, but followedup. ${ }^{22,23}$ In the controls of these cases which were followed-up for 2 and $5 y e a r s$, no shape and size differences were found in the lipomas. Since complete resection could not be carried out in our case, remaining tissue are followed-up with CT. However, no any growth was observed for a year. Because prognosis of lipoma is very good, recurrence is rare. It is believed that, lipomas have no malignant transformation and metastatic potential. ${ }^{24}$ Despite there is no malignant transformation, a case with transformation to liposarcoma has been reported..$^{16}$ Because our patient was quite relieved in terms of breathing and nutritional functions, the mass was extending to the mediastinum and the patient rejected any other intervention, our operation remained at this point. Although there is no precise data regarding the growth rate of lipoma, it has been reported that rapid weight gain enlarges lipoma and conversely weight loss does not cause difference in size..$^{24}$ Our patient is at her postoperative $1^{\text {st }}$ year with no any clinically significant patologic finding or growth found. Because intraoral resection of retropharyngeal lesions is challenging, we believe that the surgery we performed for symptomatic improvement was justified and follow-up was necessary since complete resection could not be carried out.

\section{Conclusion}

In conclusion, fibrolipomas are well contoured, slow-growing soft tissue tumors. Diagnosis is difficult as these lesions are infrequent. However, establishment of the diagnosis is easy with imaging modalities. Differential diagnosis must be definitely made. Fibrolipomas show no symptoms unless reaching to very large size. If the radiologic diagnosis in lipomateous lesions of the retropharyngeal region is compatible with lipoma and the mass causes symptoms, surgical excision is essential. Radiologic follow-up is sufficient in asymptomatic lesions since lipoma has no metastatic potential and malignant transformation is controversial.

\section{Funding}

None.

\section{Acknowledgments}

None.

\section{Conflicts of interest}

None.

\section{References}

1. Fletcher CDM, Mertens F, Unni KK. World Health Organisation Classification of Tumors. Lyon, France: IARC Press, Adipocytic tumors in Pathology and Genetics: Tumors of Soft Tissue and Bone. USA: IARC Press; 2012. 1-145 p.

2. Rosai J Ackerman's Surgical Pathology. USA: St Louis Missionary;1992;2:2053-2054.

3. Perez B, Campos ME, Rivero J, et al. Giant esophageal fibrolipoma Otolaryngol Head Neck Surg Mar. 1999;120(3):445-446.

4. Nicoli F, Balli C, Pezza VA. A case of giant fibrolipoma of the esophagus. Diagnosis using computerized tomography and double-contrast esophagography. Radiol Med. 1990;80(1-2):99-102.

5. Fregnani ER, Pires FR, FalzoniR, et al. Lipomas of the oral cavity:clinical findings, histological classification and proliferative activity of 46 cases. Int J Oral Maxillofac Surg. 2003;32(1):49-53.

6. DeFreitas MA, Freitas VS, de Lima AA, et al. Intraoral lipomas: a study of 26 cases in a Brazilian population. Quintessence Int. 40(1): 79-85.

7. Davis WL, Harnsberger HR, Smoker WR, et al. Retropharyngeal space: evaluation of normal anatomy and diseases with CT and MR imaging. Radiology. 1990;174(1): 59-64.

8. Seid AB, Dunbar JS, Cotton RT. Retropharyngeal abscesses in children revisited. Laryngoscope. 1979;89(11):1717-1724.

9. Wong YK, Novotny GM. Retropharyngeal space-a review of anatomy, pathology, and clinical presentation. J Otolaryngol. 1978;7(6): 528-536.

10. Eisele DW, Landis GH. Retropharyngeal infiltrating lipoma-a cse report Head Neck Surg. 1988;10(6):416-421.

11. Huang HC, Li HY. Retropharyngeal fibrolipoma: A counterchanging obstructive pattern in sleep apnea. İnt $\mathrm{J}$ Pediatr Otorhinolaryngol. 2009;4(1):45-48.

12. Ganakalyan B, Kumar SD. Reviewing the Entity: Retropharyngeal Fibrolipoma and a rare case report. Iran $J$ Otorhinolaryngol. 2015;2(83):469-474.

13. Ulku CH, Uyar Y, Unaldi D. Management of lipomas arising from deep lobe of the parotid gland. Auris Nasus Larynx. 2005;32(1):49-53.

14. Furlong MA, Fanburg-Smith JC, Childers EL. Lipoma of the oral and maxillofacial region:Site and subclassification of 125 cases. Oral Surg Oral Med Oral Radiol Endod. 2004;98(4):441-450.

15. Manor E, Sion-Vardy N, Joshua BZ, et al. Oral lipoma: analysis of 58 new cases and review of the literature. Ann Diagn Pathol. 2011;15(4):257-261.

16. Studart-Soares EC, Costa FW, Sousa FB, et al. Oral lipomas in a Brazilian population:a 10 year study and analysis of 450 cases reported in the literature. Med Oral Patol Oral Cir Bucal. 2010;15(5):e691-e696.

17. Namyslowski G, Scierski W, Misiolek M, et al. Huge retropharyngeal lipoma causing obstructive sleep apnea:A case report. Eur Arch Otorhinolaryngol. 2006;263(8):738-740.

18. Akhtar J, Shaykhon M, Crocker J, et al. Retropharyngeal lipoma causing dysphagia. Eur Arch Otorhinolaryngol. 2011;258(9): 458-459. 
19. Abdullah BJ, Liam CK, Kaur H, et al. Parapharyngeal space lipoma causing sleep apnea. Br J Radiol. 1997;70(838):1063-1065.

20. Kim JY, Park JM, Lim GY, et al. Atypical benign lipomatous tumors in the soft tissue: radiographic and pathologic correlation. J Comput Assist Tomogr. 2000;26(6):1063-1068.

21. Lee HK, Hwang SB, Chung GH, et al. Retropharyngeal spindle cell/ pleomorphic lipoma. Korean J Radiol. 2013;14(3):493-496.

22. Hockstein NG, Anderson TA, MoonisG, et al. Retropharyngeal lipoma causing obstructive sleepapnoea: case report including five-year followup. Laryngoscope. 2002;112(9):1603-1605.
23. Lakadamyali H, Ergun T, Lakadamyali H, et al. Giant retropharyngeal lipoma showing no change in clinical presentation and size within a two-year follow-up: a case report. Kulak Burun Boğaz Ihtis Derg. 2008;18(6):374-376.

24. Murphey MD, Carroll JF, Flemming DJ, et al. Fromthe archieves of the AFIP: benign musculoskeletallipomatous lesions. Radiographics. 2004;24(5):1433-1466. 